\title{
16 Food poverty in Kisumu, Kenya
}

\author{
George Godwin Wagah, Nelson Obange, \\ and Harun Okello Ogindo
}

\section{Introduction}

Poverty is a critical challenge for Kisumu. There have been many attempts made by government and development agencies to alleviate poverty in the city. This chapter argues that in order for poverty alleviation to be effective, it needs to be informed by an understanding of the multidimensional nature of poverty and that policies need to be informed by evidence. The experience of food security is argued here to be one means by which this multidimensionality can be examined.

Within official government articulations on food security, two dominant narratives are pervasive. The first is the presumed importance of urban agriculture as a food poverty relief strategy. The second is of a city whose population is increasing due to rural migrants to the city, who are eroding productive peri-urban land that could be used for production (see, for example, KNBS 2008). This chapter uses findings from the Consuming Urban Poverty (CUP) fieldwork to interrogate these assumptions.

While not representative of all the cities in the region, the earlier work of the African Food Security Urban Network, which investigated the food security status of selected, generally poor, communities in 11 Southern African cities, highlighted high levels of food poverty, particularly in poor neighbourhoods (Frayne et al. 2010). Through its discussion of the CUP findings, the chapter shows that food poverty is driven by more than just income poverty, supporting Mitlin and Satterthwaite's (2013) work on the multidimensionality of poverty and the notion that particular urban characteristics influence the scale and depth of poverty. The findings further illustrate that although food insecurity is most prevalent in poor areas of the city, it is a city-wide problem. The chapter then presents findings on the food source practices of households in Kisumu, highlighting the importance of market sources. The chapter concludes by returning to the dominant assumptions about potential solutions to food insecurity.

Information on the Kisumu context (its historical and economic development, its size and rate of growth, its socio-economic characteristics and spatial development) are contained in the Introduction to the book. 


\section{Poverty-food security nexus}

Traditionally, poverty is defined in either relative or absolute terms. "Absolute poverty" measures poverty in relation to the amount of income necessary to meet the basic needs of a household, such as food, clothing, and shelter. The concept of absolute poverty, however, fails to recognize that individuals have important social and cultural needs. These limitations of the "absolute" framing led to the development of the concept of relative poverty. "Relative poverty" defines poverty in relation to the economic status of other members of the society: people are poor if they fall below prevailing standards of living in a given societal context (Foster 1998). An important criticism of both absolute and relative concepts of poverty is that they are largely limited to economic units of measurements, i.e. concerned only with binary measurements of income and consumption (UNESCO 2016). Furthermore, the traditional conceptualizations of poverty considered only monetary deprivation. Multidimensional Poverty Index (MPI) measures focus on a range of deprivation factors, such as poor health, lack of education, inadequate living standards, lack of income, disempowerment, poor quality of work, and threat of violence (Alkire 2010). These two more recent conceptualizations of poverty suggest that there is an urgent need to examine income poverty and urban food insecurity, but also to enquire into food poverty as more than just the outcome of constrained income.

In developing countries, particularly within sub-Saharan Africa, urban food poverty is argued to be driven by a variety of factors including rapid urbanisation, climate change, natural disasters, and inappropriate urban food system responses to global food system changes (Tendall et al.2015). Paying attention to the nature and scale of food poverty in urban areas is not a traditional food poverty focus. When compared with rural areas general living standards tend to be better in cities; however, recent evidence suggests that urban poverty is on the rise in developing countries (Mitlin and Satterthwaite 2013). Multiple factors drive food poverty. Such factors include access to water and sanitation, spatial considerations, household structure, community networks and agency, and even factors such as a household's access to refrigeration (Battersby 2017). Urban centres in Kenya are no exception, and thus the challenges are not necessarily just hunger events and cycles that impact urban households for a short period of time, but also hunger events and cycles that appear to be more entrenched.

\section{Research method}

The 2009 Kenyan National Survey (KNS) data (KNBS/SID 2013) estimated the population of Kisumu to be 500000 , or 100000 households. Allowing for a confidence interval of $10 \%$ at a $95 \%$ level of probability, the sample size required is 383 households (using the sample size table derived from the formula by Krejcie and Morgan 1970). To enable cross-tabulation between variables, the targeted sample size was 800 . Ultimately 841 households were 
interviewed. This sample size provided a confidence interval of $7 \%$ at a $95 \%$ level of probability.

Kisumu can be divided into three discrete geographical zones:Western Kisumu (Zone A), the area west of the main A1 Road and north of the east/west B1 road; Eastern Kisumu (Zone B), located north of the B1 road and east of the A1 road; and the entire area south of the B1 road referred to as Southern Kisumu (Zone C). Colonial planning and geography of the city's growth mean that each zone contains a mix of high- and middle-income neighbourhoods, poor neighbourhoods, and peri-urban neighbourhoods. Neighbourhoods in each of these discrete zones were then purposefully selected, informed largely by ease of access (working relationships with local gatekeepers or chiefs, security, etc.) and distribution within the neighbourhood types (high-, middle-, and low-income neighbourhoods and peri-urban neighbourhoods). Two neighbourhoods of Kisumu were excluded from the sample. These were the Kaloleni neighbourhood with 3658 households and the Northern neighbourhood with 2107 households. Therefore, the sample represents the population of Kisumu excluding these two areas. The proportional nature of the sample means that it is self-weighting, so no weights needed to be calculated for the statistical analysis of the results.

The sample of households interviewed is proportional to the populations of the different geographical zones and different kinds of neighbourhood types (Table 16.1). In this respect, the sample estimates are representative of the different population sizes of these areas. The limitation of the sample design is that the three neighbourhoods selected within each neighbourhood type were not selected proportional to the size of their populations. So, to the extent that these neighbourhoods are not the same size, the sample is not an equal probability sample. Kisumu has three main informal settlement neighbourhoods one each in the south, east, and north-west - and all these were covered in the survey. More than $65 \%$ of Kisumu reside in these neighbourhoods.

The selected residential areas were further divided into sections. A systematic sampling was done, targeting every third house along a road in the formal settlements and a household in each third plot in the informal settlements. Whenever an interview in the third house/plot was not possible the next house/plot was tried until an interview was successful. The questionnaire was administered to the head of the household, or a responsible adult in the household. The quantitative survey was supported by 50 in-depth household interviews distributed across Kisumu.

The survey questionnaire applied the instruments referred to as the Food and Nutrition Technical Assistance (FANTA) tools (Coates 2013), coupled with questions aligned to the Lived Poverty Index (LPI). The FANTA tools are cross-cultural household food security measures (Crush and McCordic 2017), including the Household Food Insecurity Access Prevalence (HFIAP) measure and the Household Dietary Diversity Score (HDDS). A key motivation for the use of FANTA and LPI was to ensure that the four major dimensions of food poverty (availability, accessibility, utilization, and stability, and their links to livelihoods and the operation of the broader food system) were measured. 


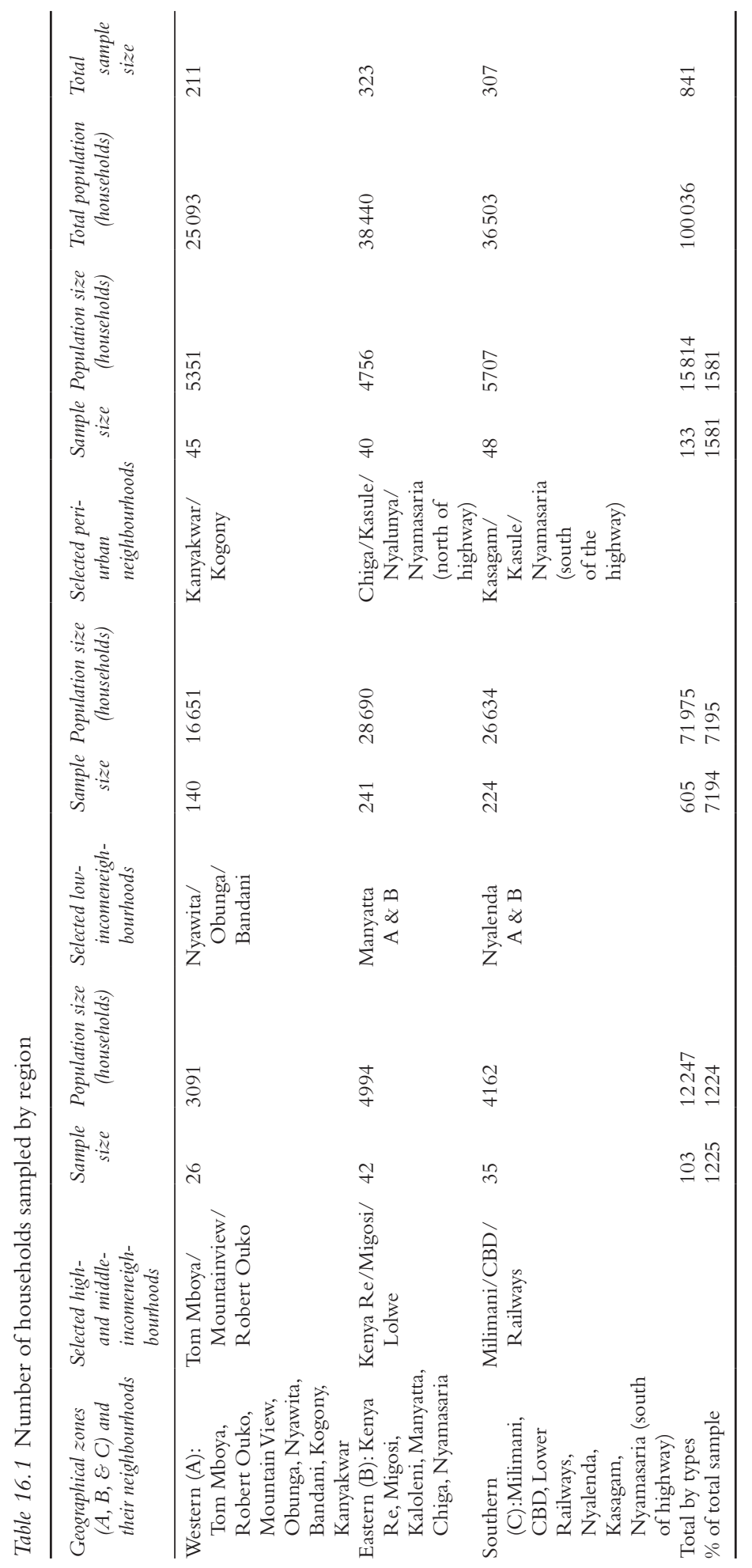




\section{Lived experiences of poverty and food poverty in Kisumu}

The average household size in the Kisumu sample was 4.16, with 49\% of households being nuclear households, 22\% female centred, 21\% extended, and 7\% male centred. The household roster data revealed two striking findings. The first was the youthfulness of the sample population. Well over half of the sampled population $(56 \%)$ were under the age of 20 , and over three-quarters $(78 \%)$ were 35 or under. Just $2 \%$ were over the age of 65 . The second was migrant status. Almost two-thirds (63\%) of the sample population were born in Kisumu, and a further $12 \%$ were born in another urban area in Kenya. Despite the narrative of rural to urban migrants driving population growth, just 25\% were born in a rural area.

The surveyed urban neighbourhoods in Kisumu have a mix of formal and informal settlement patterns which derive incomes from both formal and informal employment. Many Kisumu households rely on income from wage work in various forms. Just under a third of households (31\%) reported some income from formal wage, 30\% reported income from casual work (formal or informal), and $20 \%$ reported income from informal wage work. Households reported net income from a range of informal business types, but none of these sources were cited by more than $12 \%$ of households. Remittances, government grants and other sources of income were negligible. For employment and related labour market activities, of those of working age and eligible for employment (removing housewives, pensioners, and those with disabilities), $40 \%$ identified as self-employed, $27 \%$ reported working full time, 15\% reported working part time, $13 \%$ reported being unemployed and looking for work, and $4 \%$ reported being unemployed and not looking for work. Despite the critical role that the informal sector plays in livelihood generation (Skinner 2016), particularly in the face of high or irregular employment, the high prevalence of self and informal employment impacts on the income-generating potential of households.

The vulnerable state of employment and the general state of the economy is reflected in the sentiment held by the respondents when discussing the state of the economy. When asked to compare their current livelihood situation to previous years, $13 \%$ of households reported being better off, $35 \%$ reported the situation to be unchanged, and 50\% reported their situation being worse or far worse than the previous year.

Households were asked about their household expenditures for the month preceding the date of the interview - a 30-day recall exercise. Responses to this question offered insights into the spending profiles of households. Almost all households (96\%) reported spending on food. Other expenditure categories cited by more than half of households were fuel (64\%), housing (63\%), transportation (58\%), education (57\%), and telecommunications (53\%). While fewer households reported expenses such as debt repayments, cash remittances to rural areas, insurance, and the mutuality costs associated with family donations and support, these additional expenditure categories impact on already constrained household budgets. 
In general terms, when compared to previous years, households in Kisumu face reduced economic opportunities. Informal work dominates livelihood strategies but the income-generating potential of these activities remains constrained. There are some formal (and stable) income-generating opportunities but these are limited and, as detailed by respondents, generally low-wage opportunities (examples of formal stable income-generating opportunities include: service work in hotels, entry-level clerical work, etc.). The need for payment for certain essential services, debt repayments, and other expenses that extend beyond the immediate household (such as family support) place additional pressures on the household budgets. Given the limited number of respondents who were comfortable to report on income, the income-based poverty analysis is limited. However, it is the contention of this chapter that monetary poverty is a very narrow way of understanding poverty, and that poverty is multidimensional and needs to consider alternative, more diverse means of assessing poverty. The survey therefore made use of the LPI as a further tool to better understand the poverty. It is worth noting though that the LPI "measures a portion of the central core of the concept of poverty not captured by existing objective or subjective measures" (Mattes 2008: 161). The chapter also argues that food insecurity provides another lens through which to view poverty.

\section{The Lived Poverty Index}

Developed by Afrobarometer, the LPI is an experiential measure, based on questions about how frequently people go without basic necessities during the course of a year. The LPI is a multidimensional poverty measure assessing access to food, fuel for cooking that food, water, energy, medical treatment, and income. As LPI scores increase, lived poverty increases. The LPI of sampled households in Kisumu seems quite low, with an average LPI score for the sample of 0.90 , where 0.0 indicates that households were never without any of the categories and 4.00 indicates that households were always without all the categories. This is slightly better than the Kenyan average for 2014/2015 of 0.93 (Mattes et al. 2016: 7).

Deprivation is not uniform across the LPI categories (Table 16.2), with insufficient food to eat affecting $53 \%$ of households at some point in the previous year. Given the importance of the market as a source of food, the figure of $65 \%$ of households lacking a cash income during the previous year (Table 16.2) offers potential insights into the relationship between income and other household expenses. In addition to the lack of cash income, $57 \%$ of households had lacked enough water for home use, 50\% enough fuel to cook food, and 50\% medicine or medical treatment. These multiple deprivations shape a household's ability to ensure food security and dietary diversity. The costs of energy to cook food curtails food choice, as does access to water to clean and cook foods safely. 
Table 16.2 Reported LPI household deprivations (n819) (\% of households)

\begin{tabular}{|c|c|c|c|c|c|}
\hline $\begin{array}{l}\text { If ever, have you or your } \\
\text { household gone without. . . : }\end{array}$ & Neve & Just once or twice & Several times & Many times & Always \\
\hline A cash income? & 35 & 36 & 19 & 7 & 2 \\
\hline $\begin{array}{l}\text { Enough fuel to cook } \\
\text { your food? }\end{array}$ & 50 & 33 & 14 & 3 & 0 \\
\hline $\begin{array}{l}\text { Medicine or medical } \\
\text { treatment? }\end{array}$ & 50 & 32 & 14 & 3 & 0 \\
\hline $\begin{array}{l}\text { Enough clean water for } \\
\text { home use? }\end{array}$ & 43 & 38 & 15 & 3 & 1 \\
\hline Enough food to eat? & 46 & 31 & 19 & 4 & 0 \\
\hline
\end{tabular}

\section{Extent, depth, and nature of food insecurity in Kisumu}

Access to food is a key dimension of food poverty. This is particularly relevant in the urban context. A diverse and varied food system exists in Kisumu (see Chapter 13). Kisumu is in the midst of a food system transition, with a number of supermarkets operating adjacent to street vendors; a varied collection of outlets selling prepared food; city approved and managed food markets (including fish, fresh fruit, and vegetables); and a clustering of more informal market spaces. Production in the broader region has undergone a transformation, from local and subsistence production to intensified cash-crop production, particularly sugar, meaning that most food is imported from elsewhere in Kenya or from other countries in the region. Kisumu and the wider county is therefore a net importer of food. Food is generally accessed through the market in Kisumu, with twothirds of household reporting buying more than $75 \%$ of the food they consumed.

Urban food poverty is complex in nature: it depends not only on the buying capacity of urban citizens, but also on the ability to transport, store, preserve, and cook the foods they can afford to buy. The CUP study analyzed food availability and variety over a period of time to assess the extent of food poverty. The rest of this section will describe key food poverty indicators embedded within the suite of FANTA measures.

Levels of food insecurity, or food poverty, in Kisumu are generally high, with particularly high rates being measured in the poorer settlement areas. According to the HFIAP indicator, $71 \%$ of surveyed households in Kisumu were found to be moderately or severely food insecure, thus deemed to be experiencing food poverty. This figure, however, masks some place-specific challenges. Areas defined as peri-urban in the survey, generally those areas with higher levels of informality (and with reduced access to services), experienced particularly high levels of food insecurity. Eighty-two percent of the sampled Western peri-urban areas households, $87 \%$ of the Eastern peri-urban households, and as high as $91 \%$ of the Southern peri-urban households were moderately or severely food insecure.

The extent of food poverty is further compounded by poor dietary diversity. The HDDS tool is one measure used to assess the diversity of food consumed.The 
HDDS is a "recall question" test to identify which foods in the 12 categorized food groups were consumed by anyone in the household in the past 24 hours. A HDDS score of six or less is a proxy indicator of likely malnutrition. Over three-quarters $(78 \%)$ of households consumed food from six or fewer assessed food groups, with an average HDDS score of 4.05 items. The implication of this is a strong likelihood of both childhood stunting (which is an indicator of wellbeing and social inequality) and potential later challenges associated with obesity as a result of a low nutrient diet. The most commonly consumed food types were cereals and vegetables, specifically based on the traditional diet of ugali and sukuma wiki (green vegetables). Given the historical importance of fish within the Kisumu diet, it was surprising to see that relatively low proportions of households were consuming fish (28\%) (Figure 16.1). The survey was conducted during a period of maize meal shortages in Kisumu (the base for ugali), thus it is possible that the high price of this essential foodstuff meant that households were sacrificing dietary diversity (such as fish) in order to meet basic food needs. Household interview respondents described how a meal without ugali was "not a meal", further emphasizing its importance from a broader food security perspective.

The low levels of dietary diversity coupled with the high levels of food insecurity place a real strain on the long-term development prospects of Kisumu. Given the youthful demographic of the Kisumu sample, the challenges of stunting (a result of reduced nutrition in the first 1000 days) means that the economic potential of the population will remain constrained while the risk of further diet-related illnesses is significantly increased. The consequence is that there is a real risk that poverty will remain entrenched. These food utilization challenges are further compounded by questions of household food supply

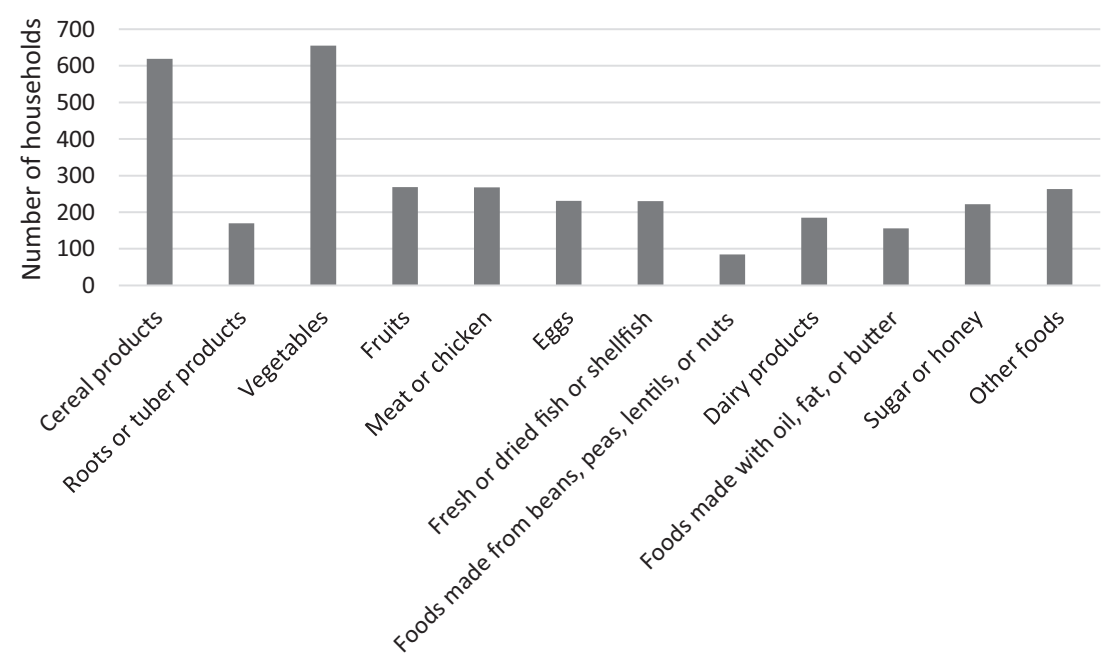

Figure 16.1 Foods eaten in the previous day (n834)

(Primary data. Author's own) 
stability. While hunger seasons are not as extreme as in other cities (see Frayne et al. 2010) the Months of Adequate Household Food Provisioning (MAHFP) in Kisumu raises important questions.

The MAHFP statistics indicate relatively stable access to food. This indicator is based on the question, "Were there months, in the past 12 months, in which you did not have enough food to meet your family's needs?" It is therefore not about the quality of the food accessible, but about a total failure of access. The average MAHFP was 10.31 , with over $80 \%$ of households having adequate access nine months or more. However, January was an outlier with $77.3 \%$ of households stating that this was a month where food access was severely constrained. August, September, and October were also challenging months but were not as extreme as January (Figure 16.2). The spike in January has been attributed largely to December festive season obligations, which include travel to certain familial areas and increased household spending, at times on costly credit, combined with the beginning of the school year.

These findings demonstrate a clear seasonality. In times of financial stress, poor households either chose to reduce certain foods, as a form of consumption smoothing, to ensure some basic foodstuffs in the house, or may simply not be able to afford certain foods. Households reported going without certain types of food because of the price of food (food being unaffordable) on a regular basis. Over a third of all households reported going without certain foods at least once a month, just less than 20\% of households reported the same on a weekly basis, and 15\% of households reported going without certain foods more than once a week. These figures reflect a highly unstable food

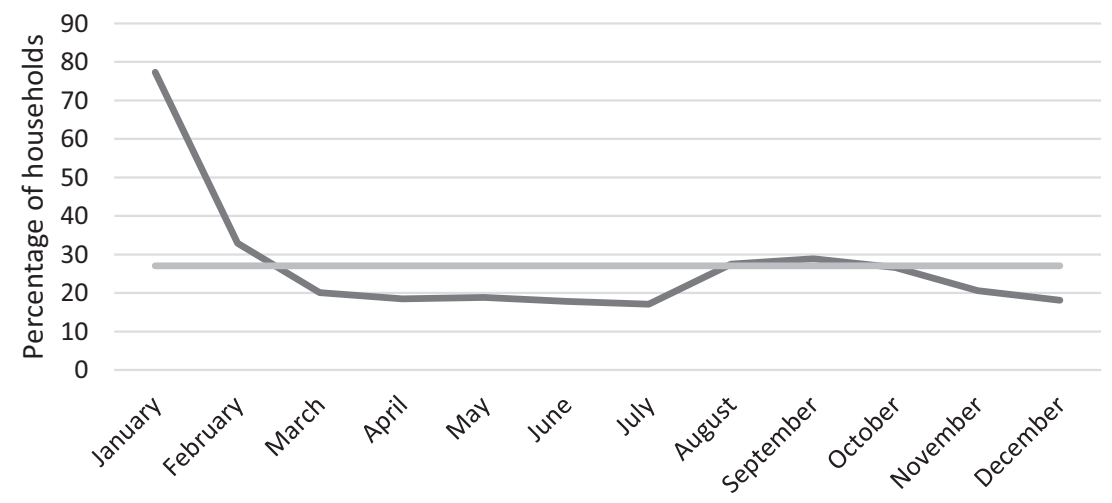

$\%$ of $\mathrm{HH}$ experiencing inadequate provisioning Average inadequate provisioning

Figure 16.2 Percentage of households experiencing inadequate food provisioning (by month) (n831)

(Primary data. Author's own) 
environment for households, an environment in which household food managers constantly have to discount certain foods in order to put food on the table.

When asked about the reasons for reduced access to food, respondents cited economic reasons linked to general household budget limitations as the key factors. The most significant reported causes of limited food access included reduced income of a household member (26\% of households), loss of or reduced employment for household members (9\%), and serious illness of a household member $(8 \%)$. Reduced food access was also attributed to more socio-political factors, including insecurity and violence (13\%) and the theft of money and food (9\%). Households did not identify the absence of refrigeration, storage limitations, and increased costs of key services such as water and energy. One conclusion is that given the long-term lack of these assets, their potential impact on food security is not recognized.

One way in which households navigate the food system is to make use of multiple food access sources. Households are highly strategic in selecting food outlets used. A decision to frequent either so-called informal traders or new supermarkets in Kisumu is not just an impulse. These outlets are selected as a result of the value provided to the households, where value is not just about cost but factors such as storage in the household, neighbourhood dynamics (not appearing wealthier than others), local transport costs versus bulk savings, and many other factors. In relation to Chapter 13, which provides greater detail on the Kisumu food system, the next section considers key food access sources, offering some insights into the wider Kisumu food system.

\section{Types of food retail outlets and household preferences in Kisumu}

Varied food retail outlets characterize Kisumu. In the survey, households were asked about the frequency at which they accessed food from a range of sources, including a range of market-based sources, own production, and various forms of non-cash-based transfers, and the importance of these sources to their food consumption. The vast majority (88\%) bought the majority of food the households consumed, demonstrating the importance of market sources. The only non-market source of food within ten most commonly used sources of food was food sent by relatives in rural areas, used by $7 \%$ of households in the last year (Table 16.3). Kiosks, market areas, and supermarkets reflect similar overall use, albeit with different use frequencies. Importantly the use frequency of the different outlets differs significantly with kiosks being frequented regularly (at least five times a week). Markets are commonly used as a weekly sourcing strategy, and supermarkets are used weekly or monthly as a source of food.

Such access strategies offer insights into the geography of food retail in Kisumu. The use frequency of the house shops and kiosks is informed by multiple factors, not just proximity to places of residence. Proximity is important given transport costs and other related costs; when the findings from the retail survey are considered, kiosks, market stalls, and even street vendors reported 
Table 16.3 Frequency of accessing food from the ten most commonly used sources of food (multiple response options) (n840)

\begin{tabular}{|c|c|c|c|c|c|c|}
\hline & $\begin{array}{l}\text { At least five } \\
\text { days a week }\end{array}$ & $\begin{array}{l}\text { At least once } \\
\text { a week }\end{array}$ & $\begin{array}{l}\text { At least once } \\
\text { a month }\end{array}$ & $\begin{array}{l}\text { At least once } \\
\text { in six months }\end{array}$ & $\begin{array}{l}\text { At least once } \\
\text { a year }\end{array}$ & Total \\
\hline $\begin{array}{l}\text { Kiosk/house } \\
\text { shop in } \\
\text { Kisumu }\end{array}$ & 532 & 111 & 4 & 1 & 0 & 648 \\
\hline Supermarket & 42 & 253 & 303 & 30 & 4 & 632 \\
\hline $\begin{array}{l}\text { Market in } \\
\text { Kisumu }\end{array}$ & 145 & 366 & 59 & 1 & 0 & 571 \\
\hline $\begin{array}{c}\text { Butcher in } \\
\text { Kisumu }\end{array}$ & 23 & 281 & 169 & 7 & 2 & 482 \\
\hline $\begin{array}{l}\text { Grinding mill } \\
\text { in Kisumu }\end{array}$ & 6 & 161 & 185 & 7 & 0 & 359 \\
\hline $\begin{array}{l}\text { Mini-market } \\
\text { in Kisumu }\end{array}$ & 109 & 107 & 7 & 0 & 0 & 223 \\
\hline $\begin{array}{l}\text { Kiosk/tuck } \\
\text { shop/vendor/ } \\
\text { trader/hawker } \\
\text { in Kisumu }\end{array}$ & 101 & 30 & 2 & 2 & 0 & 135 \\
\hline $\begin{array}{l}\text { Wholesaler in } \\
\text { Kisumu }\end{array}$ & 11 & 45 & 38 & 3 & 0 & 97 \\
\hline $\begin{array}{l}\text { Restaurant in } \\
\text { Kisumu }\end{array}$ & 13 & 20 & 27 & 3 & 0 & 63 \\
\hline $\begin{array}{l}\text { Food sent by } \\
\text { relatives in } \\
\text { rural areas in } \\
\text { this country }\end{array}$ & 0 & 1 & 17 & 35 & 7 & 60 \\
\hline
\end{tabular}

offering credit. Over $64 \%$ of traders indicated that they usually or sometimes offered credit. Regular customers, known locals, and clients with good credit were the main recipients of credit. No supermarkets reported offering credit. These locally embedded retail options serve as a vital lifeline to those struggling with food poverty, enabling further food access.

Although market-based food sources dominated, there was some use of alternative mechanisms to source food, with a small proportion sourcing food from own production. Food was also provided by neighbours and other households in communities, meals shared with neighbours, and then a collection of remittancetype food receipts. While these alternative strategies were not widespread, they remain important mechanisms to ensure food security in times of income scarcity. Households also sought to smooth income to ensure access to food. Income-pooling strategies such as social savings groups are known to operate within Kisumu and are important in addressing food purchase challenges. In the study, $22 \%$ of households indicated that they participate in table banking (network savings schemes such as stokvels or chilimba networks - locally called chama) and savings as their strategy to navigate food deficits. 
The policy discourse around food security in Kisumu centres on encouraging food production. However, just 1\% of households reported sourcing food from growing in Kisumu in the past year, and 3\% from livestock owned by the household. When asked why households did not produce their own food, the lack of land was the most commonly cited reason (59\%). However, there were a number of other reasons cited by more than 30\% of respondents, including: it is easier to buy than grow (46\%), we have no time (38\%), and people would steal what we grow (30\%). Production currently plays a minor role in the household food sourcing strategies of very few households in Kisumu. The responses to the question of why households do not produce suggest that the reasons extend well beyond a simple lack of peri-urban land, as the policy discourse suggests.

\section{Conclusion}

By using food as a lens to interrogate the relationship that Kisumu residents have with the food system, this chapter has highlighted the interconnection between lived poverty, food insecurity, and a collection of lived realities in the Kisumu context. While an important contributing factor, poverty is not just about limited income. Households engage in a constant balancing act in order to meet the costs of everyday life, and food does not always take priority. Food is key costs but households are forced to allocate funds to a variety of sources and as a result often reduce diversity in diets or even consume less food. Food poverty was found to be higher in the poorer areas, particularly the peri-urban areas, but was not unique to these areas. Using the HFIAP score $71 \%$ of Kisumu are deemed to be moderately or severely food insecure. Despite its robust and arguably diverse urban food system, the extent of food poverty in Kisumu is high, as residents are unable to utilize these food system assets to ensure food security and a diverse diet.

These findings contradict some of the existing policy imaginings within Kisumu and Kenya more broadly. Urban agriculture cannot be presumed to be the desired and viable solution to food insecurity. The food source findings in conjunction with LPI findings suggest that the problem is more systemic and requires responses beyond providing access to land. Secondly, the concern that rural to urban migrants are occupying land that would otherwise be used for production is challenged by the fact that almost two-thirds of the sample population were in fact born in Kisumu. Although $40 \%$ of household heads were born in rural areas, only $25 \%$ of the sampled population were. This suggests that population growth in Kisumu is now more a result of natural population growth. This demands a reframing of policy discourse. While rural-to-urban migration as a consequence of rural under-development is generally argued to be a driver of urban poverty, the CUP findings did not support this. Challenging these framings is essential for policy and wider governance responses. The long-term developmental and health-related consequences of the observed food poverty places the community of Kisumu at risk of continued food insecurity and long-term under-development, well into the future. 


\section{References}

Alkire, S. (2010). Acute multidimensional poverty: A new index for developing countries. Oxford: Oxford Poverty and Human Development Initiative.

Battersby, J. (2017). Cities, planning and urban food poverty in Africa. In: V. Watson, G. Bhan, and S. Srinvas, eds., Companion to planning in the global south. London: Routledge, pp. 204-214.

Coates, J. (2013). Build it back better: Deconstructing food security for improved measurement and action. Global Food Security, 2(3), pp. 188-194.

Crush,J. and McCordic, C. (2017). The hungry cities food purchases matrix: Household food sourcing and food system interaction. Urban Forum, 28(4), pp. 421-433.

Foster, J.E. (1998). Absolute versus relative poverty. The American Economic Review, 88(2), pp. 335-341.

Frayne, B., Pendleton, W., Crush, J., Acquah, B., Battersby-Lennard, J., Bras, E., ... and Leduka, C. (2010). The state of urban food insecurity in southern Africa. Urban food security series, 2. Cape Town: AFSUN.

Kenyan National Bureau of Statistics and Society for International Development (KNBS/ SID), (2013). Exploring Kenya's inequality: Pulling apart or pooling together? Nairobi: KNBS and SID.

Kenyan National Bureau of Statistics (KNBS), (2008). Constituency report on well-being in Kenya: Report based on the Kenya integrated household budget survey-2005/06. Nairobi: Government of Kenya.

Krejcie, R.V. and Morgan, D.W. (1970). Determining sample size for research activities. Educational and psychological measurement, 30(3), pp. 607-610.

Mattes, R. (2008). The material and political bases of lived poverty in Africa: Insights from the Afrobarometer. In:V. Møller, D. Huschka, and A.C. Michalos, eds., Barometers of quality of life around the globe. Social Indicators Research Series, Vol 33. Dordrecht: Springer, pp. 161-185.

Mattes, R., Dulani, D. and Gyimah-Boadi, E. (2016). Africa's growth dividend? Lived poverty drops across much of the continent. Afrobarometer Policy Paper No. 29, January 2016. Available at: http://afrobarometer.org./sites/default/files/publications/Policy\%20papers/ab_ r6_policypaperno29_lived_poverty_declines_in_africa_eng.pdf [Accessed 1 May 2018].

Mitlin, D. and Satterthwaite, D. (2013). Urban poverty in the global south: Scale and nature. Abingdon: Routledge.

Skinner, C. (2016). Informal food retail in Africa: A review of evidence. Consuming Urban Poverty Project, Working Paper 2. Cape Town: African Centre for Cities.

Tendall, D., Joerin, J., Kopainsky, B., Edwards, P., Shreck, A., Le, Q.B., . . and Six, J. (2015). Food system resilience: Defining the concept. Global Food Security, 6, pp. 17-23.

UNESCO,(2016). International migration. Retrieved March 12, 2017.Available at: www.unesco. $\mathrm{org} / \mathrm{new} / \mathrm{en} /$ social-and-human-sciences/themes/international-migration [Accessed 15 Mar. 2017]. 